\title{
ESCRITA COREOGRÁFICA DIGITAL: NOVAS PERSPECTIVAS SOBRE O PROCESSO CRIATIVO EM DANÇA
}

Daniele Castro*

RESUMO: Nas últimas décadas do século $X X$, coreógrafos e bailarinos presenciaram o surgimento de softwares para notação e criação em dança. Uma tecnologia cuja promessa é facilitar a escrita coreográfica e preservar sequências de movimento que antes estariam sob a guarda apenas da memória de seus criadores e intérpretes. Porém, para além de seus benefícios mais evidentes, é preciso investigar as implicações de tais tecnologias na compreensão do processo criativo de dança e do estatuto do corpo do bailarino. Recorrendo a estudos específicos sobre o tema e considerações dos principais criadores e utilizadores de tais tecnologias, este artigo procura confrontar diferentes perspectivas sobre a relação entre a escrita da dança e a tecnologia, tendo como eixo norteador o pensamento sobre o papel do corpo e da sensibilidade humana no processo criativo.

PALAVRAS-CHAVE: Criação. Coreografia. Corpo. Dança. Tecnologia.

\section{Coreografar sem corpos: questões iniciais}

Na década de 1990, o norte-americano Merce Cunningham criava suas coreografias durante viagens de avião, utilizando o programa DanceForms instalado em seu notebook: um software de animação capaz de simular os movimentos de um bailarino em três dimensões. Dessa maneira, ele indicava que, até certo ponto, o processo de criação em dança poderia prescindir de bailarinos reais, preterindo a sua presença física em favor de simuladores virtuais. Esse episódio ilustra a aproximação cada vez mais recorrente entre as artes performáticas e a tecnologia, permitindo que mesmo os olhares menos atentos percebam que o corpo, nesse contexto, se afasta de sua típica materialidade para também habitar o terreno da "virtualidade".

Os caminhos que a arte tecnológica toma, na atualidade, são diversos, mas todos eles parecem permeados pelo impacto da digitalização. Vivemos um momento de

\footnotetext{
*Universidade Federal do Rio de Janeiro, Rio de Janeiro, Brasil. E-mail: danielepcastro@gmail.com 
transição da cultura material para a imaterial, e pincéis, tintas, massas, telas, instrumentos musicais, entre outros artefatos da arte tradicional, são preteridos em favor da intangibilidade dos bits, fomentando a elaboração de uma série de obras que circulam exclusivamente no cibersespaço, ou que são produzidas preferencialmente com o uso de equipamentos eletrônicos e precisam da interação com o público para se consumarem. E quanto às artes do corpo, vale indagar: como elas estão inseridas nesse contexto de abandono da materialidade em favor de uma gradativa e veloz digitalização? Que usos a performance e a dança podem fazer das tecnologias da computação, se o corpo ainda não pode ser digitalizado?

Neste artigo, investigamos o uso de softwares para a criação coreográfica. Eles contribuem com o trabalho do coreógrafo, proporcionando muitas facilidades práticas: dispensam a necessidade de espaço e tempo adequados e o tornam independente em relação à disponibilidade dos bailarinos. No entanto, para além de tais facilidades, interessa-nos saber o que essa inexigibilidade da materialidade carnal indica sobre o corpo que dança: se ele está invariavelmente conectado a um ser humano, a simulação do corpo a partir de atributos matemáticos não estaria, portanto, excluindo esse "ser" do processo de criação? Que mudanças dispositivos como esse deixam antever em relação ao estatuto daquele que dança? Para esta investigação, recorremos a escritos de coreógrafos que trabalham com este tipo de software, bem como a estudos sobre o mesmo tema. Diferentes pontos de vista convivem em uma multiplicidade que demonstra a coexistência de entendimentos contrastantes sobre o processo de criação artística. Por um lado, existe uma preocupação com a "porção humana" do ato criativo que não pode ser abarcada pela linguagem digital. No entanto, por outro lado, há divergências sobre em que consiste efetivamente essa humanidade e se ela não pode, afinal, ser alterada pela própria pregnância da tecnologia nos processos artísticos.

Assim, surgem questões como: uma máquina é capaz de criar artisticamente? Ou apenas nós, seres humanos, possuímos o dom de gerar objetos que possuam valor estético? A resposta a tal indagação passa, obviamente, pela definição do que é a arte, mas não apenas. Paralelamente, é preciso discutir o que caracteriza o humano e o que identifica o maquínico, bem como aquilo que os separa. As tecnologias avançam 
para um patamar em que são capazes de substituir o corpo humano pelo menos tecnicamente. Por exemplo, atualmente, robôs assumem o lugar das mãos de cirurgiões e conseguem, inclusive, superá-los em termos de precisão. Esses profissionais deslocam-se das mesas para as telas, operando as máquinas que acabam por mediar a relação entre médico e paciente. No entanto, algo ainda é indiscutível: quem opera é o cirurgião, e não a máquina. Porém, cabe aqui a pergunta: e se esse robô fosse capaz de funcionar de maneira autônoma?

No campo da arte, a complexidade assume ainda outro nível. Não existindo um resultado objetivo a ser conquistado, a máquina torna-se menos submissa aos desígnios de seu operador. Isso quer dizer que não se trata do artista, tal qual o cirurgião, fazer do robô as suas mãos, mas de incorporar ao processo da obra e, consequentemente, ao seu resultado, as características operacionais da máquina. Assim, o objeto de arte criado nessa relação não se assemelha àquele que foi gerado apenas pelas mãos do artista, ou seja, não é o mesmo fim por outros meios, pois, nesse caso, os meios determinam o fim. A tecnologia modifica substancialmente o processo criativo e, consequentemente, seu resultado final, a obra. No caso da escrita coreográfica digital, tal mudança parece ainda mais radical ao excluir do processo um elemento que, junto ao movimento, é o mais fundamental da dança: o corpo.

\section{Primeiros softwares para criação coreográfica: o gênio artista na berlinda}

O primeiro registro de uso de um software para a criação coreográfica data da década de 1960, quando Jeanne Beaman e o cientista computacional Paul Le Vasseur, da Universidade de Pittsburgh, criaram um programa capaz de gerar, randomicamente, uma sequência de eventos a partir de uma lista de movimentos. Anos depois, na década de 1970, John Lansdown, um dos pioneiros da computação gráfica, explorou o potencial do design para criar coreografias, entre outros projetos artísticos. Seu trabalho resultou, ao longo dos anos, em uma série de papers nos quais problematizou questões sobre a natureza da computação e da arte. Ele indicava, já naquela época, o ponto crucial da discussão sobre o encontro entre a linguagem computacional e a criação artística: os aspectos da arte tradicionalmente atribuídos à subjetividade e, portanto, difíceis de serem traduzidos para a objetiva sintaxe da máquina. 
“Computadores não têm 'pensamentos', 'emoções' ou 'sentimentos' - coisas que muitas pessoas consideram pré-requisitos essenciais para a criação em arte e design"1, afirmava Lansdown (LANSDOWN in RUITER, 1988, p. 147). No entanto, ele próprio questionou: será que a "emoção" reside no próprio objeto artístico ou naquele que o vê?

Essas palavras ilustram uma mudança de paradigma, já em andamento nos anos 1970, que diz respeito à elaboração do sentido da obra de arte. No início do século $X X$, teve início um questionamento do papel do artista como gênio criador, através de obras que exploravam novos suportes e métodos. São exemplos disso os readymades $^{2}$ de Duchamp e o cadavre exquis ${ }^{3}$ dos surrealistas. A ensaiada ruptura com o padrão tradicional de arte, porém, tomou maior impulso na década de 1960, tendo como um dos principais fatores de propulsão o diálogo com novos suportes midiáticos e tecnologias. Tais recursos permitem a realização de obras que exigem do espectador uma postura mais participativa e menos contemplativa. Assim, a relação espectador/obra se reconfigura. Abandonando o esquema tradicional associado ao suporte material, à contemplação e à visão, ela caminha em direção a um arranjo no qual o processo, a participação e a fruição através de múltiplas sensibilidades são elementos que adquirem maior importância. Delineiam-se, portanto, os contornos de uma arte na qual o sentido da obra é dado mais pelo olhar da recepção e menos pela intenção da autoria. Deixa a cena, então, a figura do artista como gênio e criador bem como a noção da obra como uma expressão de seus pensamentos e emoções - em prol daquele que a vê e que participa da sua criação através de suas ações e sua sensibilidade ${ }^{4}$.

\footnotetext{
${ }^{1}$ Tradução da autora.

${ }^{2}$ Objetos industriais, ou seja, não criados pelo artista, deslocados de seu contexto real para o universo da arte.

${ }^{3}$ Método coletivo de construir uma obra, através da junção de palavras ou imagens de maneira mais ou menos aleatória.

${ }^{4}$ Quanto a isso, para evitar eventuais equívocos de interpretação, é preciso ressaltar a análise atenta de Paula Sibilia sobre o tema da autoria: não se trata de um declínio do mito do autor, mas de um deslocamento que se efetua com a desvinculação entre o artista e sua obra. Nos dias atuais, a personalidade do autor é exaltada pela mídia e pelo mercado, e a obra é relegada para segundo plano. De acordo com a pesquisadora, apesar da recorrente temática da hibridização entre autor e espectador, conclamadas pelos entusiastas da interatividade, em certo sentido não seria possível afirmar que a tão anunciada "morte do autor" se efetivou, pois esta figura retornou em outros moldes: o autor não é mais aquele que faz ou cria alguma coisa, mas aquele que é alguém e, como tal, se torna visível porque aparece. (SIBILIA, 2008, p. 188)
}

Texto Digital, Florianópolis, Santa Catarina, Brasil, v. 12, n. 1, p. 99-118, jan./jun. 2016. ISSNe: 1807-9288. 
Tendo em vista tais mudanças, Lansdown (in RUITER, 1988, p. 147-148) defende que não é apropriado encararmos o computador apenas como uma ferramenta passiva para auxiliar o artista na feitura do seu trabalho artístico. Afinal, não é o caso de simplesmente mudar os instrumentos - no lugar de pincéis e telas, softwares e hardwares - , mas de inaugurar uma nova maneira de fazer arte, promovendo a participação do espectador através da ativação de sua sensibilidade e de seu poder de dar sentido à obra. A tecnologia da computação aparece, portanto, como um dispositivo capaz de alterar nossa visão sobre o que chamamos arte e design. Desse modo, Lansdown reconhece que o uso dos computadores coloca em andamento um processo de reconfiguração de todo o campo da arte que modifica os modos de fazer, redefine o que é uma obra e, sobretudo, questiona diversos aspectos da condição humana e seu papel na criação artística.

Entre os pontos principais da estética proposta por Lansdown, que envolve o uso da computação gráfica, cabe destacar a ênfase no processo em contraposição à obra acabada. Emerge a preocupação com os princípios que regem a criação, entre eles, a aleatoriedade ou a estrita preocupação com as regras e com a possibilidade de que a arte seja produzida a partir de outras motivações, deixando de ser tributária de uma tradicional força criativa que provém da emoção, da experiência e da intuição, ou seja, da interioridade de cada artista. Também é atribuída ao espectador a responsabilidade pelo significado da obra, ou seja, ele deve procurar um sentido para aquilo que vê, percorrendo as estruturas e as conexões entre imagens, palavras e movimentos através de sua própria discricionariedade. Nos textos de Lansdown, percebemos que o uso da computação na arte está relacionado a um declínio do papel de certos aspectos da subjetividade do autor na criação, o que, pelo menos na dança, caracterizará a superação do movimento moderno em vários pontos.

\section{Merce Cunningham: o acaso e a tecnologia desafiam o corpo}

O coreógrafo Merce Cunningham foi o grande precursor de uma nova maneira de pensar a criação artística na dança cênica, trazendo definitivamente a tecnologia e o acaso para o processo coreográfico. Para começar a explorar esse campo, vale 
destacar uma importante característica do trabalho de Cunnigham, conforme identificado pela pesquisadora Carrie Noland (2009): seu esforço para que os elementos de decisão do processo criativo fossem resultantes de meios objetivos ou externos, e não subjetivos. Cabe lembrar que o artista foi bailarino da companhia de Martha Graham, uma das mais importantes coreógrafas da dança moderna. No entanto, distanciou-se dos preceitos de tal companhia ao propor uma dança que buscava a neutralidade emocional. Muitas de suas práticas são fruto de sua parceria com o compositor John Cage, que utilizava em suas músicas métodos nada ortodoxos de composição, como a aleatoriedade e as estruturas de tempo matematicamente precisas. O que estava em jogo era uma nova ideia de continuidade, na qual as conexões entre as partes não se regiam por relações de causa e efeito, temáticas comuns ou a motivação emocional, mas pelo acaso, aproximando-se, assim, de um método também muito utilizado nas artes plásticas: a colagem.

No início, Cunnigham lançou mão de recursos manuais para tornar suas decisões aleatórias: uma moeda decidia a ordem em que as sequências de movimento seriam engajadas; depois, ele desenvolveu um método para fazer combinações entre tempo, espaço e movimento, através de gráficos desenhados em um papel. Tais dispositivos, intitulados chance operators, não foram utilizados apenas para conectar as sequências, mas serviram para criar os próprios movimentos. O coreógrafo dividia o corpo em partes, relacionava as possibilidades de movimento e se valia do acaso para determinar quando e como cada parte do corpo estaria se movendo. O resultado, obviamente, eram movimentos muito difíceis de serem executados pelos bailarinos, pois - tal qual pretendia Cunningham - os afastavam das formas habituais de se mover, exigindo do corpo a habilidade desafiadora de realizar o não-familiar, o nãointuitivo e o não-natural. Noland ratifica tudo isso: "ao longo dos anos, entrevistas com os bailarinos de Cunningham confirmaram que o grande desafio que eles enfrentavam era a ampliação de sua habilidade de fazer uma sequência de movimentos nunca antes encadeados seja no dia-a-dia ou na aula de técnica tradicional" (NOLAND, 2009). ${ }^{5}$

\footnotetext{
${ }^{5}$ Tradução da autora.

Texto Digital, Florianópolis, Santa Catarina, Brasil, v. 12, n. 1, p. 99-118, jan./jun. 2016. ISSNe: 1807-9288.
} 
Antes disso, contudo, a ideia de uma continuidade aleatória já tinha aparecido como elemento de criação. A própria Carrie Noland (2009) ressalta que as estéticas dadaísta e surrealista apostavam em um novo tipo de encadeamento. No entanto, essas propostas diferem dos projetos de Cunningham por visarem a objetivos diferentes, resultantes de concepções também distintas sobre o que é a arte. Os primeiros viamnas claramente como parte de um projeto político, apostando no poder libertário da espontaneidade e do automatismo psíquico, contrariando a normatização disciplinadora vigente de modo hegemônico naquela época. Já a arte do coreógrafo aqui abordado, por sua vez, apesar de também possuir seu caráter político, não tinha - e nem pretendia ter - absolutamente nada de espontânea ou intuitiva. Se, para os vanguardistas do início do século $\mathrm{XX}$, o acaso significa ir contra as regras tradicionais da arte e da vida social naquele momento histórico, para Cunningham, o acaso implica ir contra a arte que se pretende intuitiva.

\begin{abstract}
Antes da Primeira Guerra Mundial, a sequência de eventos materiais na arte era determinada - ou ao menos pensava-se que era determinada organicamente, subjetivamente, ou de acordo com princípios convencionais (narrativos, prosódicos, representacionais). Em resumo, a continuidade resultava de uma lógica reconhecível atribuída à natureza, à psicologia ou à tradição artística. Com a invenção das tecnologias de produção de continuidade, como o método para fazer um poema dadaísta de Tristan Tzara ou cadavre exquis, a fonte da continuidade foi explicitamente deslocada em direção a dispositivos externos, ao acaso ou a processos objetivos. A ênfase dadaísta (e surrealista) estava, teoricamente, não na criação de trabalhos artísticos mas em desenterrar um tipo de realidade pré-consciente, nãointencional, e coletiva que não poderia ser acessada ao menos que métodos convencionais de sequenciamento fossem alijados [...] No entanto, Cunningham salienta que sua maior razão para empregar procedimentos aleatórios não é encontrar uma verdadeira, mais profunda realidade, mas simplesmente gerar alternativas possíveis para realizar as potências virtuais do corpo $^{6}$. (NOLAND, 2009)
\end{abstract}

Portanto, a partir dos estudos de Lansdown e da obra de Cunnigham, é possível perceber dois aspectos importantes dessa nova estética: a origem motivacional da criação, que deixa de se apoiar em elementos considerados subjetivos (emoções, intuição, gênio do autor) para se voltar a fatores considerados objetivos (regras, estruturas, acaso). E, no caso da dança, o princípio que rege a relação do ser humano com seu corpo, que se desloca da obediência a uma "ordem orgânica", estabelecida

\footnotetext{
6 Tradução da autora.

Texto Digital, Florianópolis, Santa Catarina, Brasil, v. 12, n. 1, p. 99-118, jan./jun. 2016. ISSNe: 1807-9288.
} 
e fixa, em direção à sua superação por meios técnicos. Esses são pontos de dissenso entre a obra de Cunningham e seus predecessores modernos. A intenção da coreógrafa Martha Graham, por exemplo, era criar uma técnica que estivesse em consonância com a natureza do corpo humano, suas funções orgânicas e, assim, possibilitasse a mais sincera expressão do espírito. Por outro lado, Cunnigham aposta na "inorganicidade" dos movimentos e das sequências determinadas pelos seus chance operators, bem como na liberação da dança de seu compromisso com a expressão de emoções ou com a representação.

\section{A escrita coreográfica digitalizada: novas perspectivas sobre a criação}

Uma vez liberada a dança de seu comprometimento com as motivações subjetivas para a criação, bem como com o respeito à organicidade do corpo e com a obediência a uma lógica interna à obra, ficou aberta a via para o uso da computação como um dispositivo de criação coreográfica. Cunningham começou a fazer uso do software DanceForms no ano de 1991. Trata-se de um software que permite a criação de coreografias através de figuras animadas em ambiente 3-D (fig. 1). Em sua versão 2.0, o sistema vem com uma biblioteca de movimentos de técnicas tradicionais como o balé - com adicionais específicos referidos à escola russa e à italiana - , além de uma biblioteca de movimentos de dança moderna e vistas diferenciadas — do público, das laterais do palco e do fundo - , possibilitando a adição de contagem de tempo e som. E, ainda, traz sequências de passos que auxiliam no treinamento e no aprendizado. ${ }^{7}$

\footnotetext{
${ }^{7}$ Os dados sobre o software estão disponíveis no site da empresa Credo Interactive, responsável por sua projeção e comercialização. Disponível em:

http://charactermotion.com/products/danceforms/index.html Acesso em: 01 mai 2015.
}

Texto Digital, Florianópolis, Santa Catarina, Brasil, v. 12, n. 1, p. 99-118, jan./jun. 2016. ISSNe: 1807-9288. 
Fig. 1 - Tela do programa Danceforms.

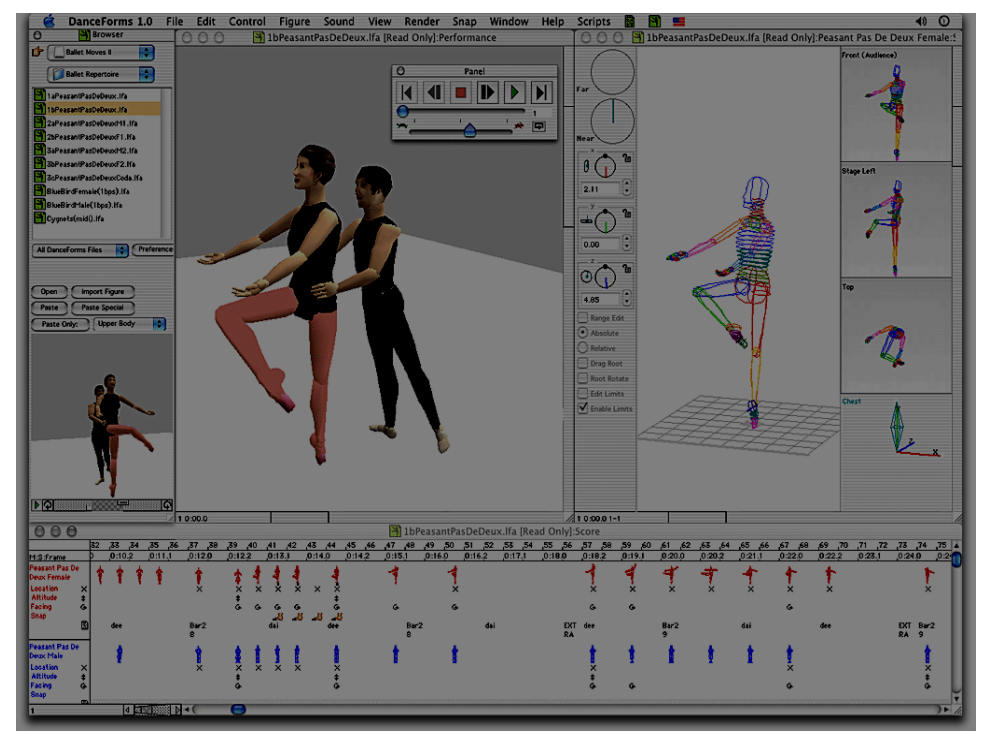

Sem mais alongar a descrição desse software, a intenção é apenas mostrar em que patamar se encontra esse tipo de tecnologia para que ela chegue ao ponto de ser capaz de substituir um bailarino humano. Em termos de simulação dos movimentos do corpo, dos ângulos de visão possíveis, das projeções das formas em relação ao tempo e ao espaço, talvez o programa tenha atingido um nível ótimo. No entanto, cabe perguntar: se a dança se caracteriza por ser uma arte inseparável do corpo humano, o que é deixado de lado quando um coreógrafo opta por criar sem a presença física de seus bailarinos? Há diferença entre uma dança criada com o uso de softwares de simulação e outra elaborada com a participação de corpos humanos? Que tipo de entendimento sobre a arte, sobre o corpo, sobre o ser humano e sobre a tecnologia está implicado nesse tipo de fazer artístico? Longe de poder responder satisfatoriamente a essas perguntas, pretende-se colocar em discussão alguns aspectos relevantes de tais tecnologias que ainda não foram suficientemente explorados. Além da existência e do uso desse tipo de ferramenta e tendo em vista a definição de "tecnologia" aqui utilizada, acredita-se que a perspectiva de análise deve ser ampliada de forma a abarcar, afora os dispositivos, as diversas transformações nas crenças e valores relacionados ao advento de novas maneiras de lidar com o corpo e de compreender a arte.

Para começar tal incursão nesses novos modos de criar artisticamente, convém 
explicar, recorrendo a um exemplo brasileiro, que motivações levaram à construção dos programas de simulação de dança. Parece que, na maioria dos casos, tais dispositivos se originaram a partir de sistemas de notação de movimentos, que são muito importantes para o registro das obras. Esse é o caso do primeiro software para criação coreográfica surgido no Brasil, que foi resultado da preocupação de uma bailarina com o problema da memória histórica da dança. Analívia Cordeiro criou, na década de 1980, o Nota-Anna, como um sistema de notação capaz de preservar as coreografias de maneira semelhante a uma partitura musical. Para elaborá-lo, buscou inspiração nos sistemas de notação já existentes e nas experiências de computerdance e computer-animation. Mais tarde, a artista começou a utilizar o programa para criar coreografias destinadas à televisão. De acordo com Cordeiro (1976, p.50), o uso do computador diminui as falhas de comunicação entre coreógrafo e bailarino, pois as ideias do primeiro podem ser representadas em forma de uma escrita de movimento mais objetiva e mais fácil de ser entendida. Através desse método, a artista pretendeu substituir as metáforas normalmente utilizadas pelos coreógrafos para transmitir suas ideias: por um lado, a linguagem verbal, que tem o problema de não ser capaz de expressar adequadamente um movimento; por outro lado, a expressão corporal, que limita o caráter individual do bailarino, pois ele passa a imitar os gestos do coreógrafo.

De acordo com a criadora do Nota-Anna, o movimento é basicamente trajetória. Por isso, o sistema privilegia esse aspecto ao buscar a representação ideal, deixando outros - como a forma ou a força - em segundo plano. O quesito força, inclusive, é apontado pela autora como a porção individual de expressão que cada bailarino imprimirá ao movimento criado e transmitido pelo coreógrafo através do computador. Ao privilegiar a trajetória sobre outros aspectos, Cordeiro (1996, p.08) enfatiza que não há necessidade de que o símbolo represente uma figura humana.

A notação fornecida pelo computador deve induzir, principalmente, a expressividade do bailarino-aluno, pois em dança o movimento transmite uma mensagem clara e atinge sua significação com a intenção gestual e a sutileza interpretativa. Não existe, em nenhum momento, o objetivo de transformar os dançarinos reais em desenho animado. (CORDEIRO, 1996, p. 11)

John Lansdown (in RUITER, 1988, p. 147) identifica quatro formas de uso da computação na arte: como ferramenta, em que o computador é utilizado para executar 
tarefas de maneira menos trabalhosa; como meio, quando o computador é utilizado como suporte da obra de arte; como catalisador, quando ele usado como forma de inspirar novas abordagens criativas; e, por último, como um aprendiz inteligente, ou seja, utilizando-o como um assistente que teria "inteligência" para explorar novas possibilidades e abordagens. No caso do Nota-Anna, sendo um sistema de notação, parece que o computador ainda funciona basicamente como uma ferramenta. Entretanto, quando utilizado para a criação, ele pode modificar de maneira bastante profunda a relação do bailarino com a coreografia.

Muitos coreógrafos elaboram suas obras a partir de experiências, jogos e improvisos realizados nas salas de ensaio, agindo como catalisadores de processos criativos que envolvem todo o grupo. Em métodos como esses, os movimentos não habitam, desde sempre, a "cabeça" do coreógrafo, mas se originam nas respostas dos bailarinos aos problemas apresentados. Isso quer dizer que a coreografia é resultado de um trabalho de provocação, seleção, decupagem, edição e aperfeiçoamento dos movimentos elaborados a partir do envolvimento dos participantes com o processo. Portanto, o resultado final carregará consigo elementos da força criativa de cada um. Nesse tipo de trabalho, costuma-se considerar que os bailarinos são intérpretes-criadores, salientando sua importância na composição da obra. Assim, se a criação for realizada através do computador, unicamente pelo coreógrafo, em que medida há o risco de se perder essa contribuição dos bailarinos no processo de elaboração da obra? É claro que isso diz respeito ao método de cada companhia, pois, mesmo sem o uso de um software de simulação, cada uma pode promover diferentes níveis de participação de seus bailarinos no processo criativo e cada obra pode ser elaborada de maneira mais ou menos coletiva. Foi aqui descrito um procedimento de caráter bastante colaborativo. No entanto, é importante atentar para as implicações do uso do computador no processo de interpretação-criação a que são submetidos os bailarinos. Cordeiro (1976), por exemplo, ressalta que o Nota-Anna não retira do bailarino sua potência individual de expressão, pois o programa deixa muitos elementos indeterminados que podem ser supridos pela ação de cada bailarino no momento de execução do movimento. Em suas próprias palavras: 
Os intérpretes, na sua atuação, devem executar os elementos fornecidos. Estes são considerados pelo coreógrafo indispensáveis para a transmissão da mensagem. Aqueles considerados indeterminantes são deixados em aberto, para que o intérprete crie seu caráter. (CORDEIRO, 1976)

Contudo, é evidente que ainda há uma larga diferença entre os dois procedimentos. No primeiro, o bailarino é criador; no segundo, ele é apenas um intérprete que terá mais ou menos liberdade - dependendo das brechas deixadas pelo coreógrafo para imprimir sua marca na execução do movimento. Podemos fazer uma analogia com o texto de uma peça dramatúrgica. $\mathrm{O}$ ator, ao representar o texto de teatro pronto, interpreta aquilo que lê. Portanto, ele emprega - nos limites da liberdade permitida em cada caso - um pouco de sua própria forma de se expressar artisticamente. Mas, nesse caso, o intérprete não pode ser considerado um criador.

Outra questão importante a ser ressaltada diz respeito às idiossincrasias do corpo de cada bailarino. A elaboração de movimentos no campo informático não leva em conta questões como força, flexibilidade, energia, peso ou agilidade, aspectos que são extremamente variáveis mesmo em um único indivíduo. De acordo com Cunningham, porém, essa seria uma vantagem, pois, ao se deparar com um movimento muito difícil para seu corpo, o bailarino teria que buscar meios para superar tais limitações. Entretanto, o desafio ao bailarino não é o único aspecto implicado nessa maneira de criar: uma coreografia elaborada com o uso de figuras programadas no computador terá provavelmente um resultado estético diferente daquela criada com a participação física dos bailarinos desde o início do processo. A linguagem digital não é apenas uma ferramenta que facilita a criação, mas ela se torna a própria matéria a partir da qual a obra é criada.

Um exemplo prático pode esclarecer melhor o argumento aqui proposto: uma maneira de compor em dança é "criar no corpo do bailarino", quer dizer, modelá-lo como uma escultura viva, dando-lhe instruções sobre os movimentos, o emprego de energia e a velocidade, entre outros aspectos importantes, e incorporando também a maneira desse corpo se "comunicar" através da dança. Assim, o coreógrafo não estará apenas em condições de respeitar as limitações e potências de cada um - se assim o desejar — mas também poderá visualizar no próprio ato o verdadeiro resultado estético de 
suas ideias, o que depende, especialmente, das características físicas individuais (e talvez também não apenas físicas) de cada bailarino. Ao contrário, quando simulado por computador, o corpo é “objetivado", pois é construído a partir de certos parâmetros fixos que privilegiam os aspectos anatômicos padronizados - tais como os movimentos dos músculos e as articulações - e os espaciais - como posições e deslocamentos - não dando conta de incorporar as inconstâncias e peculiaridades que caracterizam cada corpo humano. Resta perguntar se, na referida maneira de o bailarino se "comunicar" através da dança, estão implicados apenas os já mencionados aspectos físicos, ou se algo mais se perde quando o ser humano é simulado por uma figura programada em computador.

Assim como nas aspirações de Cordeiro, na maioria dos casos, a construção de softwares para elaboração de coreografias é consequência da transferência, para o computador, de alguma linguagem de notação, como, por exemplo, a Labanotation. ${ }^{8}$ O interesse, em primeira instância, costuma ser a necessidade de lidar com a problemática da memória da dança. No entanto, a capacidade de edição de dados da linguagem digital e a simulação de figuras humanas em ambiente 3D possibilitaram ir além, atingindo a criação de interfaces e sistemas de animação em dança. Em um trabalho bastante informativo sobre esse assunto, Royce James Neagle lista e descreve vários sistemas de animação em dança disponíveis atualmente. Entre eles, estão os programas NUDES e LabanDancer Interface, que permitem visualizar figuras animadas utilizando softwares de edição da Labanotation, além do já citado DanceForms e outros programas mais comerciais, tais como o Cal3D.

Em sua pesquisa, Neagle (2005) constatou que "os aplicativos que fazem interface com os softwares editores de notação não focam nas diferentes qualidades do movimento relacionadas à expressividade". Em vez disso, "eles criam uma sequência animada de dança, e não uma performance animada de dança" 9(NEAGLE, 2005). Com relação ao balé, Neagle afirma que o performer tenta expressar suas próprias emoções ou os sentimentos da personagem interpretada através de dois aspectos

\footnotetext{
${ }^{8}$ Sistema de notação criado pelo coreógrafo Rudolf Von Laban em 1928.

9 Tradução da autora.

Texto Digital, Florianópolis, Santa Catarina, Brasil, v. 12, n. 1, p. 99-118, jan./jun. 2016. ISSNe: 1807-9288.
} 
constituintes da dança: os gestos definidos pela coreografia e a qualidade empregada no movimento - quer dizer, a maneira como o gesto é executado. A limitação dos métodos de notação e animação reside no fato de que, apesar de conseguirem representar a sequência de gestos, não são capazes de tornar visíveis as noções de sentimento e personalidade. Ainda de acordo com este autor e tendo em vista que ele faz referência apenas ao balé, a ideia de "qualidade do movimento" diz respeito à expressão de emoções, sentimentos e personalidade, sejam elas do performer ou da personagem que ele interpreta. A representação do gesto pelos sistemas de notação e animação seria, por consequência, incompleta, pois estes ainda não possuem recursos para incluir tais aspectos em seus simuladores.

Há de se ressaltar, porém, que nessas formulações se postula certo entendimento dos fatores que constituem o gesto, a qualidade de movimento e a dança, o qual é apenas um dentre tantos possíveis. Essa concepção sobre a dança como um meio de expressão de sentimentos é predominantemente romântica, tendo sido largamente reivindicada pelo mestre de balé Jean-Georges Noverre no século XVIII. Mais tarde, no século XIX, provocou profundas modificações na maneira como se encenava um balé, permitindo que ele se tornasse uma arte de maior importância no período romântico.

A expressividade de cunho sobretudo representativo serviu para sedimentar as bases do balé, que até hoje é a mais popular das danças cênicas. No entanto, a ideia de "qualidade do movimento" como a transmissão de emoções e sentimentos está longe de ser unânime no universo da dança na atualidade. Ao contrário, há outros aspectos mais valorizados: a interatividade, as sensações corporais, o processo, a plasticidade do movimento - enfim, todos elementos que não evidenciam a necessidade de representar emoções através do gesto. Vale perguntar, então, se o problema seria realmente o de uma limitação da tecnologia em relação à representação da emoção veiculado pelo movimento dançando, ou se a própria maneira como se entende a dança, o gesto e a qualidade de movimento já teria se reconfigurado, permitindo o surgimento e a popularização desses novos recursos técnicos. É possível supor que, antes de serem limitados nesse ponto, os softwares aos quais nos referimos estão, ao contrário, adequados àquilo que atualmente se espera da dança: talvez não 
precisem representar sentimentos, emoções e personalidade, pois tais elementos já não são tão essenciais à dança como o eram para o balé romântico.

Há, porém, outras objeções a serem formuladas quanto ao uso da linguagem computacional para simular os movimentos dançados. A artista Erin Manning, diretora do Sense Lab, um laboratório de investigação do corpo sensitivo e sua capacidade de conhecimento do mundo, também considera que essa tecnologia apresenta limitações em sua capacidade de simular o gesto. No entanto, no lugar da representação de emoções, sua preocupação focaliza o estabelecimento, pela linguagem digital, de bases rígidas de enquadramento do corpo e seus movimentos. Manning (2007) escreveu um texto no qual questiona a maneira como a "dança tecnológica" tem sido realizada, alegando que a criação de uma gramática do movimento própria à linguagem do computador acaba por amarrar o corpo a uma compreensão préestabelecida, impondo uma estabilidade que retém a capacidade de inovação sensível. De acordo com essa artista, o mapeamento do gesto quebra o movimento em bits, quando o melhor seria tentar preservá-lo em sua totalidade.

De fato, os programas de computador que propõem a simulação de figuras humanas em movimento dançado fazem-no através de informações numéricas distribuídas em pacotes de dados, que, depois de complicadas operações matemáticas, aparecem para os usuários através de uma interface gráfica. "A imagem calculada por pontos é uma imagem quantificada e, por sua natureza de matriz numérica, permite o acesso ao seu tecido em pequenas microunidades que aceitam modificações" (DOMINGUES, 1997, p.22). Para que essas informações numéricas possam ser reconhecidas, traduzidas e editadas, precisam estar organizadas conforme parâmetros próprios dessa linguagem.

Seguindo um percurso semelhante, um grupo interdisciplinar de professores das universidades de Bucknell e Warwick, composto por Kelly Knox, Ann-Christine Frandsen e Elton G. McGoun (2010), trabalha com a hipótese de que a linguagem da computação não tem a capacidade de descrever todos os aspectos do movimento dançado. Para elaborar seu argumento, os pesquisadores partem do princípio de que não é possível traduzir todo o conhecimento que temos do mundo em equações 
matemáticas ou através da linguagem verbal. Isso porque a inteligência não é apenas uma faculdade mental, mas possui também uma porção corpórea e sensível, que eles denominam embodied knowledge — literalmente, conhecimento encarnado. Isso seria o que escapa à representação por dados numéricos ou verbais. Nenhum sistema de notação se mostra, portanto, suficiente para explicitar todas as nuances dessa arte; e, se houvesse algum capaz de fazê-lo, provavelmente seria complicado demais para ser utilizado na prática. Nada garante que os bailarinos conseguirão executar os movimentos criados por meio dos aplicativos que unem a notação às figuras animadas. Contudo, por conta da mesma capacidade que torna difícil transformar a dança em dados - o caráter sensível e encarnado da maneira humana de estar no mundo os autores vislumbram com certo otimismo as possibilidades trazidas por essa união entre a tecnologia da notação e a criação. Quando o ser humano interpreta dados, não o faz apenas com sua mente ou com sua inteligência objetiva, mas utiliza também o conhecimento encarnado e a sensibilidade. Levando-se em conta essa propriedade da percepção, os pesquisadores se perguntam se o vocabulário da tecnologia não poderá realmente gerar um novo corpo em movimento, abrindo caminho para modalidades sensíveis antes inexploradas.

Nos casos descritos, as objeções em relação à "dança tecnológica" dizem respeito a aspectos do ser humano considerados subjetivos: no primeiro caso, a emotividade ou a singularidade individual; nos dois seguintes, a sensibilidade ou a plasticidade corporal. No entanto, a posição de desconfiança, no lugar de afastar os autores de projetos que visam à aproximação entre dança e tecnologia, provoca um efeito contrário: faz com que sejam empregados esforços para conseguir, de alguma maneira, abarcar tais aspectos na linguagem da computação. Segundo os próprios autores, portanto, as críticas que produziram não significam uma total descrença na possibilidade de uma simbiose entre a tecnologia e o ser humano, mas sua desaprovação em relação a como essa aproximação vem sendo realizada na dança. Eles parecem acreditar que seria possível desenvolver métodos ou dispositivos pelos quais a tecnologia seja capaz de identificar, descrever, simular e até mesmo modificar os atributos mais subjetivos da condição humana.

\section{Conclusão - Redefinições do corpo e da sensibilidade}

Texto Digital, Florianópolis, Santa Catarina, Brasil, v. 12, n. 1, p. 99-118, jan./jun. 2016. ISSNe: 1807-9288. 
Os artistas aqui analisados apostam na possibilidade de existir uma boa parceria entre a tecnologia e o corpo humano, desde que continue presente a sensibilidade que conduz o ofício de uma ação meramente mecânica em direção ao fazer artístico. Difícil é definir o que é e onde reside essa sensibilidade. Lansdown diria que ela se hospeda na recepção, no espectador que vê a obra. Analívia Cordeiro, por sua vez, localiza-a no intérprete: no bailarino que, pela ação da energia de seu corpo, cede ao movimento puro toda a coloração que o tornará dança. Caberia acrescentar que há fatores históricos agindo nessas transformações e deslocamentos do lócus. Cada época abriga suas próprias maneiras de pensar a experiência sensível e explicar os efeitos e causas da arte sobre o que consideramos o "ser humano". Nos dias atuais, parece que a tendência é crer que a tecnologia e a sensibilidade humana não estão reciprocamente imunes ou são autônomas, nem tampouco se reduzem uma à outra, mas se entrelaçam de um modo complexo. Em um diálogo entre essas duas instâncias, portanto, acredita-se que elas possam transcender a si mesmas em direção a uma unidade que, particularmente no campo da arte, poderá proporcionar novas experiências aos seres humanos.

Essa crença é defendida tanto no âmbito da produção quanto nos estudos teóricos em arte tecnológica em torno do argumento principal da construção de um tipo de "sensibilidade artificial". Segundo Maria Teresa Cruz, o espaço imaterial e lógico do digital está "a adquirir, pelo menos tendencialmente, a densidade e a tangibilidade próprias daquilo que podemos tocar e com o qual nos podemos relacionar sensorialmente e, até mesmo, emocionalmente" (CRUZ, 2000, p. 3). Além de alterações na capacidade cognitiva humana, as tecnologias digitais têm atuado também sobre o corpo, principalmente no âmbito da sensorialidade. Assim, estaria em andamento uma transformação e um alargamento das atividades perceptivas humanas, "no interior do qual a atual diversidade dos sentidos (visual, auditivo, tátil, etc...) seria redefinida, re-hierarquizada e possivelmente acrescentada" (CRUZ, 2000, p. 8). Esse processo de redefinição do aparato sensório humano se daria por meio da "tradutibilidade absoluta de todos os dados sensíveis em informação e da informação em tangibilidade" (CRUZ, 2000, p. 8). A partir deste entendimento, vale pensar sobre o seguinte tópico: criar em dança através de softwares de simulação realmente elimina 
a porção humana desse processo ou tratar-se-ia, afinal, de uma redefinição do que é o humano?

De acordo com tal argumento, não é o caso de se manter uma mesma concepção a respeito da criação em dança e pensarmos nas restrições impostas pelo uso desse tipo de tecnologia, mas, assim como propôs Lansdown, investigar como se reconfigura o corpo no processo de criação e, por conseguinte, como isso muda a obra. Cruz (1999, p. 3-4) analisa a utilização de programas computacionais para a criação de pinturas ${ }^{10}$ e chega à conclusão de que a máquina, na verdade, não substitui o artista, mas aliena seu gesto. Se o pintor, tal qual o bailarino, apenas executa a posteriori o que a manipulação da máquina lhe propõe, acontece uma estranha inversão de papeis: a máquina produz e o artista reproduz. Assim, o gesto do pintor ou do bailarino, que seria o encontro entre a criatividade e seus respectivos procedimentos técnicos, estaria reduzido apenas ao segundo termo. O corpo, nesse processo, não é substituído. Pelo contrário, ele continua sendo indispensável à arte. No entanto, é profundamente reconstituído, passando por um novo programa de adestramento a partir da técnica e sofrendo amputações, complementações e potenciações.

Do outro lado dessa relação, a máquina não incorpora o gesto do artista, ou seja, ela não pinta ou coreografa, apenas funciona. Afinal, conforme ressalta Cruz, "se os gestos de interação com a máquina são eles próprios antecipáveis e programáveis, então não são gestos, mas sim operações" (CRUZ, 1999, p. 7). O que poderia, então, resgatar o gesto desaparecido do artista nessa arte tecnológica? Teresa Cruz ensaia uma resposta: segundo ela, o que poderia haver de mais interessante no funcionamento de uma máquina é a introdução do elemento de variação que existe naquele que funciona com a máquina, naquele que se relaciona com ela. Seria preciso, para isso, sair da condição de utilizador, de mero operador, o que implicaria "extrair gestos das nossas máquinas" (CRUZ, 1999, p. 7).

\footnotetext{
${ }^{10}$ Maria Teresa Cruz cita especificamente o caso de AARON, um computador capaz de criar pinturas originais. O robô foi inventado por Harold Cohen, diretor do Centro de Pesquisas em Computação e Artes (CRCA) em San Diego, California.
} 


\section{DIGITAL CHOREOGRAPHIC WRITTEN: NEW PERSPECTIVES ON THE CREATIVE PROCESS IN DANCE}

ABSTRACT: In the last decades of the twentieth century, choreographers and dancers witnessed the emergence of softwares for notation and creation in dance. A technology whose promise is to facilitate the choreographic writing and preserve sequences of movements that before were only under the guard of the memory of their creators and interpreters. However, beyond its most obvious benefits, it is necessary to investigate the implications of such technologies on understanding of dance's creative process and the status of dancer's body. Through specific studies on the subject and considerations of the leading developers and users of such technologies, this article seeks to confront different perspectives on the relationship between the writing of dance and technology, thinking about the role of the body and sensitivity human in the creative process.

KEYWORDS: Creation. Choreography. Body. Dance. Technology.

\section{Referências}

CORDEIRO, Analívia. Nota-Anna: uma notação trajetória dos movimentos do corpo humano. 1996. Resumo de dissertação de mestrado - Instituto de Artes, Universidade Estadual de Campinas, Campinas, 1996.

. O coreógrafo programador. Rio de Janeiro: 1976. Disponível em: <http://analivia.com.br>. Acesso em: 4 mar. 2011.

CRUZ, Maria Teresa. Da nova sensibilidade artificial. Imagens e reflexões, Edições Universitárias Lusófonas, Lisboa, 2000. Disponível em: <http://bocc.ubi.pt/pag/cruzteresa-sensibilidade-artificial.html>. Acesso em: 10 mai. 2015.

DOMINGUES, Diana. A humanização das tecnologias pela arte. In: DOMINGUES, Diana. A arte no século XXI: a humanização das tecnologias. São Paulo: Unesp, 1997, p. 15-30.

KNOX, Kelly; FRANDSEN, Ann-Christine; MCGOUN, Elton G. Dancing the Dow: Accounting and Financial Information Embodied. Sixth Asia Pacific Interdisciplinary Research in Accounting (APIRA 2010). University of Sidney. Julho, 2010. Disponível em: <http://apira2010.econ.usyd.edu.au/conference_proceedings/>. Acesso em: 1 mai. 2015

LANSDOWN, John. Computer graphics: a tool for the artist, designer e amateur. In: RUITER, M.M. Advances in computer graphics III. Aire-la-Ville, Suiça: Eurographic, 1988. p. $147-175$.

MANNING, Erin. Prosthetics making sense: dancing the technogenetic body. Concordia University, Montréal. Disponível em: <http://erinmovement.com/>. Acesso em: 1 mai. 2015 
NEAGLE, Royce James. Emotion by motion: expression simulation in virtual ballet. 2005. Tese - School of computing, Faculty of engineering, University of Leeds School of Computing, Leads, 2005. Disponivel em:

<http://etheses.whiterose.ac.uk/1331/>. Acesso em: 1 mai. 2015.

NOLAND, Carrie. Coping and choreography. In: Digital Arts and Culture Conference, 2009, University of California, California, USA. Proceedings of the Digital Arts and Culture Conference, 2009. Disponível em:

<https://escholarship.org/uc/item/0gq729xq\#page-3>. Acesso em: 1 mai. 2015.

SIBILIA, Paula. O show do eu: a intimidade como espetáculo. Rio de Janeiro: Nova Fronteira, 2008.

Recebido em: 01/05/2015.

Aceito em: 17/12/2015. 